Supporting Information

\title{
Green toughness modifier from downstream corn oil in improving poly(lactic acid) performance
}

\author{
Suman Thakur, ${ }^{a}$ Erick O. Cisneros-Lopez, ${ }^{a}$ Jean-Mathieu Pin, ${ }^{a}$ \\ Manjusri Misra, ${ }^{a, b *}$ and Amar K. Mohanty ${ }^{a, b *}$
}

a Bioproducts Discovery and Development Centre, Department of Plant Agriculture, Crop

Science Building, University of Guelph, 50 Stone Road East, Guelph, Ontario, N1G 2W1, Canada

${ }^{\mathrm{b}}$ School of Engineering, Thornbrough Building, University of Guelph, 50 Stone Road East, Guelph, Ontario, N1G 2W1, Canada

*Email: mmisra@uoguelph.ca (MM), mohanty@uoguelph.ca (AKM) 


\section{Characterization}

NMR experiments were recorded in a Bruker AVANCE III spectrometer with a ${ }^{1} \mathrm{H}$ operating frequency of $600.0 \mathrm{MHz}$ and a ${ }^{13} \mathrm{C}$ operating frequency of $150 \mathrm{MHz}$, using a $5 \mathrm{~mm}$ TCI cryoprobe. $\mathrm{CDCl}_{3}$ was used as a solvent for $\mathrm{ECO}$ and $\mathrm{MIECO}$, whereas $\mathrm{D}_{6}$-acetone was used for MI. The sample temperature was kept at $22{ }^{\circ} \mathrm{C}$ for all the NMR testing.

Fourier-transform infrared spectroscopy (FTIR) spectra of the samples were obtained using an attenuated total reflectance (ATR) device on a Thermo Scientific Nicolet 6700 FTIR. The background was collected before capturing the spectra for each sample. The experiment was performed in the $4000-500 \mathrm{~cm}^{-1}$ wavenumber range with 64 scans per specimen.

Thermogravimetric analysis (TGA) of the PLA-MIECO blends was performed using a TGA Q500 from TA-Instruments, USA under the nitrogen atmosphere. The samples weights with approximately $10-13 \mathrm{mg}$ were ramp heated from $30^{\circ} \mathrm{C}$ to $700^{\circ} \mathrm{C}$ with a heating rate of $10^{\circ} \mathrm{C} / \mathrm{min}$. To study the crosslinking density of PLA-MIECO blends, about $1 \mathrm{~g}$ of each blends $\left(\mathrm{m}_{1}\right)$ was immersed in $50 \mathrm{~mL}$ of chloroform for $24 \mathrm{~h}$ separately to dissolve PLA and un-cross-linked MIECO. Then, the insoluble part was collected via centrifugation and washed with chloroform three times. After that the isolated part was vacuum-dried at $50{ }^{\circ} \mathrm{C}$ for $12 \mathrm{~h}$ and weighted as $\mathrm{m}_{2}$. The crosslinking density of the blend was calculated as the equation 1

$\frac{\mathrm{m}_{2}}{\mathrm{~m}_{1} \times \mathrm{X}_{\text {MIECO }}} \times 100 \%$

where $\mathrm{X}_{\mathrm{MIECO}}$ is the weight fraction of MIECO in the blends.

\section{Dynamic mechanical analysis}

Dynamic mechanical analysis of PLA-MIECO blends was carried on a Q800 DMA (TA instruments, USA). Samples were equilibrated at $-30{ }^{\circ} \mathrm{C}$ for $10 \mathrm{~min}$ and then heated at $3{ }^{\circ} \mathrm{C}$ $\min ^{-1}$ to $120^{\circ} \mathrm{C}$. A periodic deformation of $0.02 \%$ strain was applied at $1 \mathrm{~Hz}$ in dual cantilever 
mode. Periodic deformation of $0.02 \%$ strain was used to perform the test in the linear viscoelastic regime. The storage $\left(\mathrm{E}^{\prime}\right)$ to $\operatorname{loss}\left(\mathrm{E}^{\prime \prime}\right)$ modulus ratio $(\tan \delta)$ was plotted as a function of the temperature.

\section{Mechanical Testing}

Tensile and flexural properties were tested in an Instron universal testing machine (Instron, Canada) following the procedures outlined on ASTM standards D638 and D790. A crosshead speed of 5 and $14 \mathrm{~mm} / \mathrm{min}$ was used for tensile and flexural testing respectively. Notched Izod impact testing was performed according to the procedures outlined on ASTM D256 using an impact tester equipped with a hammer of $0.5-5 \mathrm{ft}$. $1 \mathrm{bs}$. Impact samples were notched $48 \mathrm{~h}$ prior to testing. All samples were kept undisturbed in sealed plastic bags at room temperature for 2 days prior to testing. Five specimens were tested for determination of tensile, flexural and impact properties.

\section{Differential Scanning Calorimetry}

Differential scanning calorimetry (DSC Q200, TA Instruments) of MI, MIECO and PLAMIECO blends was performed under the nitrogen atmosphere $(50 \mathrm{~mL} / \mathrm{min})$. Samples of about 10-15 mg were weighed and placed in a closed aluminum pan. First, the samples were heated from room temperature to $200{ }^{\circ} \mathrm{C}$ at a rate of $10^{\circ} \mathrm{C} / \mathrm{min}$ followed by a cooling cycle at $5{ }^{\circ} \mathrm{C} / \mathrm{min}$ until reaching $-60^{\circ} \mathrm{C}$. Finally, samples were heated again at a rate of $10^{\circ} \mathrm{C} / \mathrm{min}$ until $200^{\circ} \mathrm{C}$. A slower cooling rate has been performed to allow full crystallization of the samples. As PLA crystallizes slowly so it needs enough time to reach equilibrium crystallinity. Data from the second heating cycle was considered for analysis of thermal properties of the materials. The glass transition temperature $\left(\mathrm{T}_{\mathrm{g}}\right)$, cold crystallization peak $\left(\mathrm{T}_{\mathrm{cc}}\right)$, and melt peak temperature $\left(\mathrm{T}_{\mathrm{m}}\right)$ 
were obtained from the DSC curves. The degree of crystallinity $\left(X_{c}\right)$ for PLA was calculated from the following equation $2:{ }^{1}$

$X_{c}=\frac{\Delta H_{m}-\Delta H_{c c}}{\Delta H_{0}}$

where $\Delta \mathrm{H}_{\mathrm{m}}$ and $\Delta \mathrm{H}_{\mathrm{cc}}$ are the melting and cold crystallization enthalpies of the blends, respectively, $\Delta \mathrm{H}_{0}$ is the theoretical melting enthalpy of a completely crystalline PLA (93.6 J/g). ${ }^{1}$ $\Delta \mathrm{H}_{\mathrm{m}}$ and $\Delta \mathrm{H}_{\mathrm{cc}}$ values are normalized by the weight fraction of PLA. The enthalpy values are calculated by TA universal analysis. A linear baseline was used for the integration in the enthalpy peak. Concerning the exothermic event before the melting peak, it has been taken into account for the melting enthalpy calculation.

\section{SEM Imaging}

Scanning electron images were obtained from impact and tensile fractured specimens on a Phenom ProX scanning electron microscope (Phenom-World VB, The Netherlands). Samples were coated with a fine layer of gold prior to observation to provide a protective layer for preventing the deformation at high magnifications. 


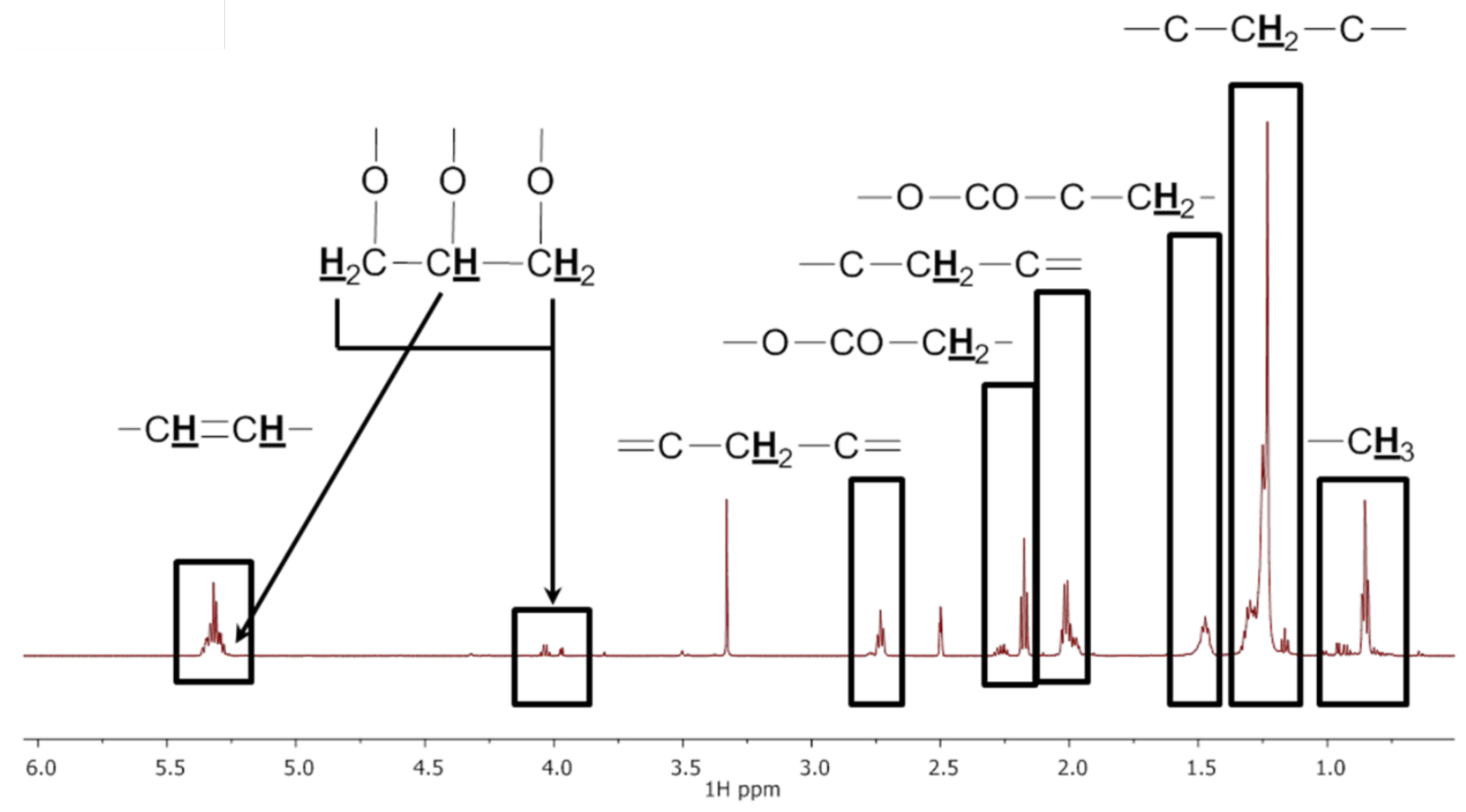

Figure S1 ${ }^{1} \mathrm{H}$ NMR spectrum of DCO

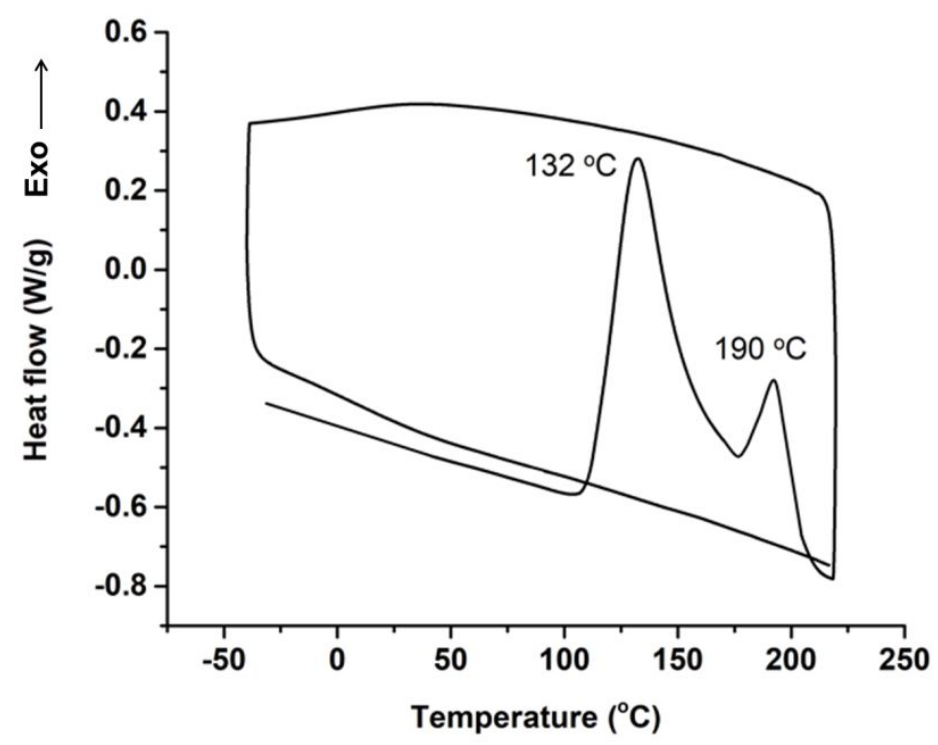

Figure S2 DSC curve of MIECO with 1phr Luperox; showing two exothermic peaks. 


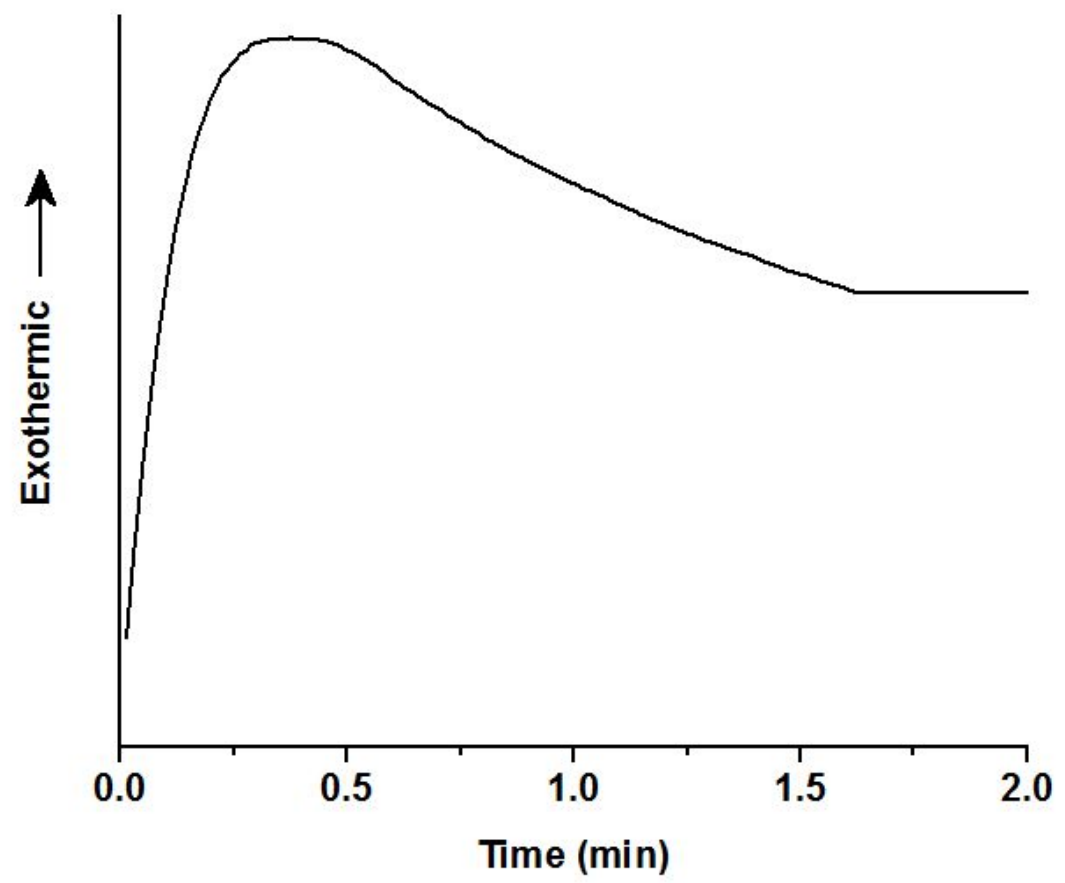

Figure S3 Isothermal DSC curve of MIECO with $1 \mathrm{phr}$ Luperox at $180^{\circ} \mathrm{C}$.

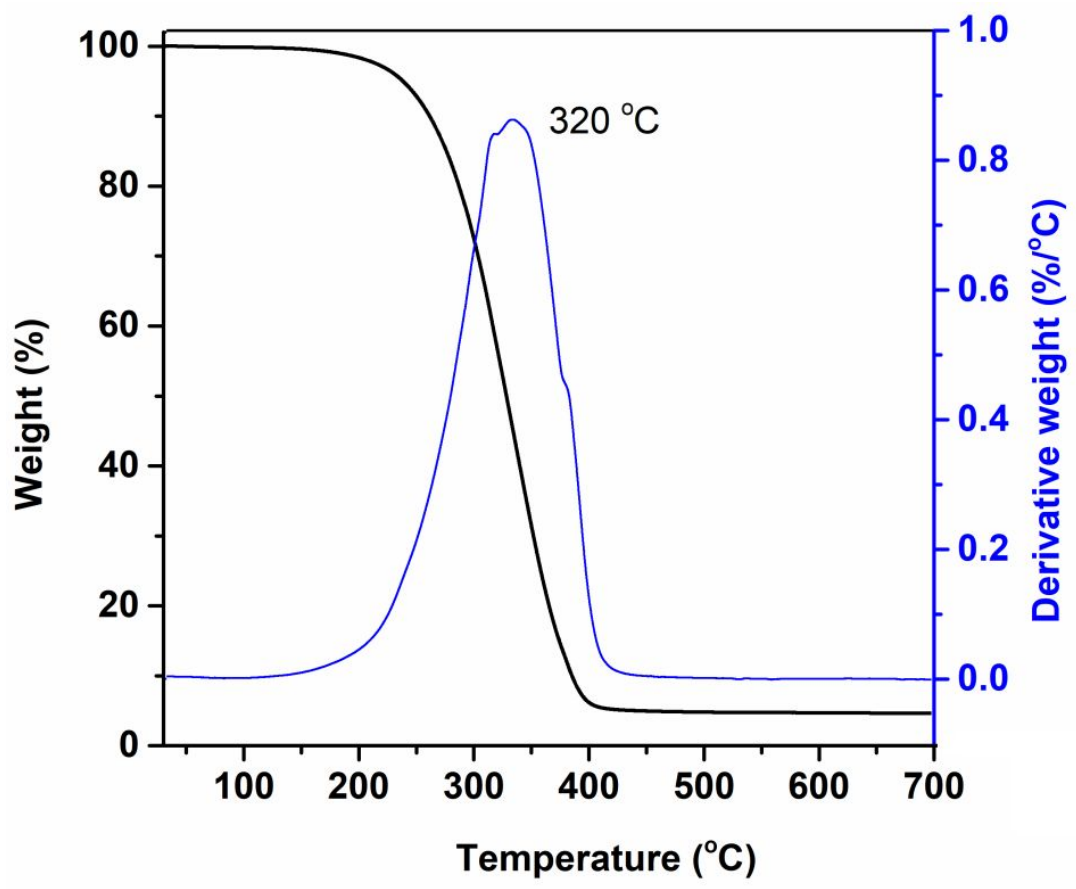

Figure S4 TGA curve of MIECO 


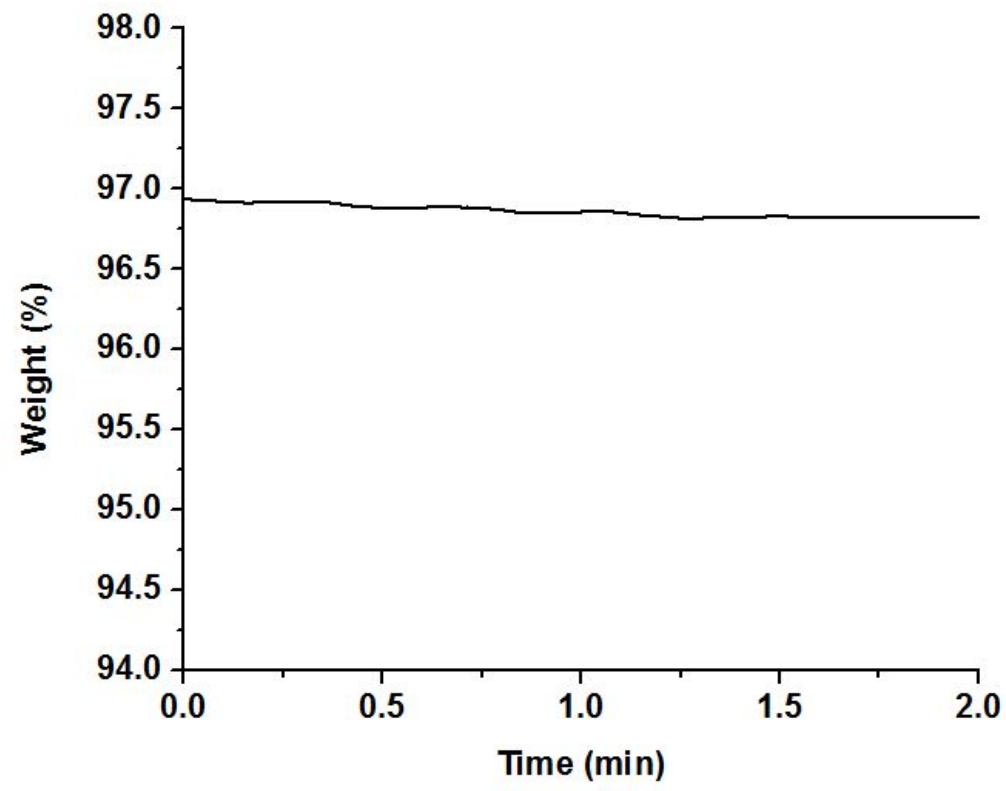

Figure S5 Isothermal TGA curve of MIECO at $180^{\circ} \mathrm{C}$

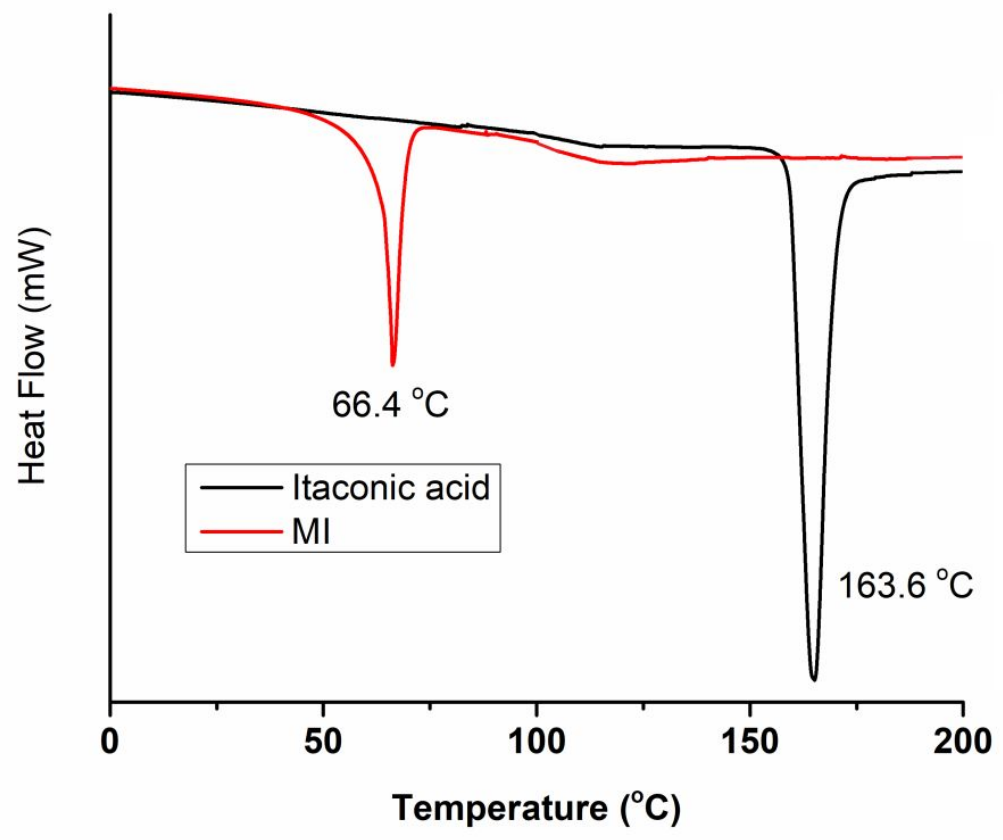

Figure S6 DSC curve of itaconic acid and MI 


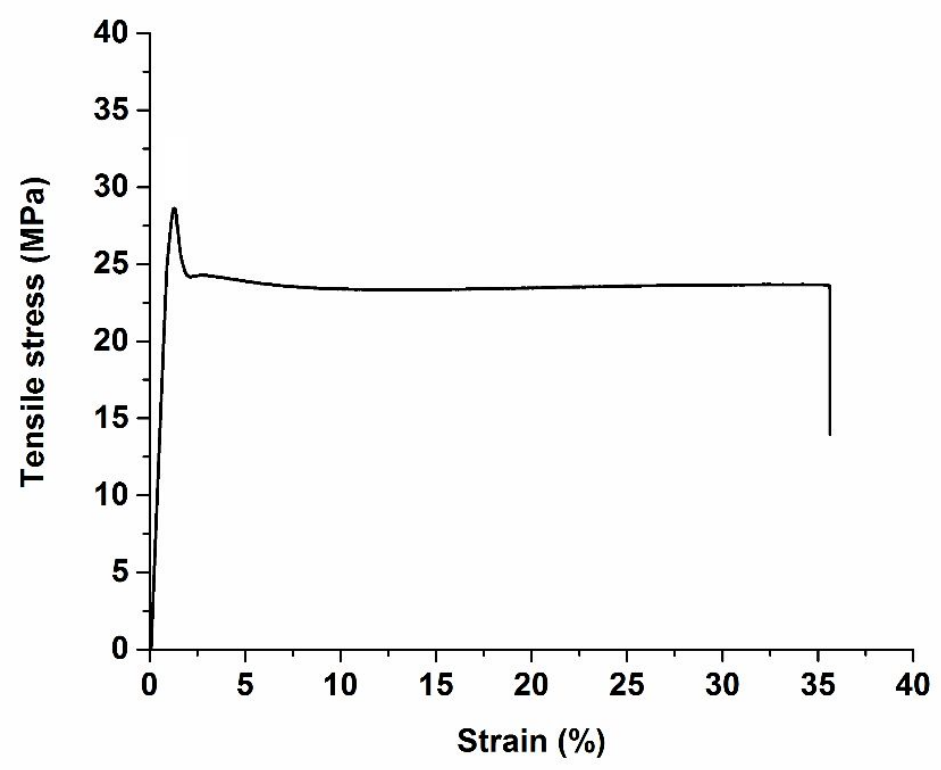

Figure S7 Stress-strain curve of PLA blend with 10\% downstream corn oil (without modification) 
Table S1 Comparison of mechanical properties PLA/ multifunctional reactive vegetable oil blend

\begin{tabular}{|c|c|c|c|}
\hline Blend & $\begin{array}{l}\text { Tensile strength } \\
\text { (MPa) }\end{array}$ & $\begin{array}{l}\text { Elongation at break } \\
(\%)\end{array}$ & Reference \\
\hline PLA & $64 \pm 2$ & $4.1 \pm 0.9$ & \multirow[t]{5}{*}{2} \\
\hline PLA/soy bean oil & $44 \pm 3$ & $24 \pm 14$ & \\
\hline PLA/AESO & $62 \pm 1$ & $31 \pm 39$ & \\
\hline PLA/AESO/soybean oil & $44 \pm 4$ & $20 \pm 9$ & \\
\hline PLA/AESO/soybean oil/STAR & $44 \pm 1$ & $39 \pm 6$ & \\
\hline PLA & $65.9 \pm 1.8$ & $5.3 \pm 1.0$ & \multirow[t]{2}{*}{3} \\
\hline PLA/AESO (5\%) & $64.6 \pm 0.7$ & $7.3 \pm 0.4$ & \\
\hline PLA & 66 & 5.1 & \multirow[t]{3}{*}{4} \\
\hline PLA/AESO (5\%) & 63 & 7.4 & \\
\hline PLA/AESO $(10 \%)$ & 59 & 10.6 & \\
\hline PLA & 66 & 4.97 & \multirow[t]{3}{*}{5} \\
\hline PLA/MHO (5\%) & 99.8 & 7.3 & \\
\hline PLA/MHO (10\%) & 88.3 & 11.6 & \\
\hline PLA & 63.2 & 10 & \multirow[t]{3}{*}{6} \\
\hline 10PESO/PLA & 55.1 & 19 & \\
\hline 40PESO/PLA & 21.9 & 141 & \\
\hline PLA & 64 & 6.5 & \multirow[t]{3}{*}{7} \\
\hline PLA/MLO5 & 51 & 28 & \\
\hline PLA/MLO20 & 38 & 78 & \\
\hline PLA & 46.8 & 4 & \multirow[t]{4}{*}{8} \\
\hline PLA/MCSO2.5 & 43.9 & 5.8 & \\
\hline PLA/MCSO5 & 40.2 & 12.9 & \\
\hline PLA/MCSO7.5 & 37 & 15.7 & \\
\hline PLA & $72 \pm 0.99$ & $2.57 \pm 0.27$ & \multirow{4}{*}{$\begin{array}{l}\text { This } \\
\text { work }\end{array}$} \\
\hline PLA-MIECO5 & $56.4 \pm 1.47$ & $27.76 \pm 2.98$ & \\
\hline PLA-MIECO10 & $46.9 \pm 1.15$ & $39.41 \pm 6.02$ & \\
\hline PLA-MIECO15 & $37.1 \pm 1.23$ & $47.14 \pm 8.99$ & \\
\hline
\end{tabular}

$\mathrm{AESO}=$ Acrylated epoxidized soybean oil, $\mathrm{PESO}=$ polymerized epoxidized soybean oil, $\mathrm{MCSO}=$ maleinized cottonseed oil, $\mathrm{MHO}=$ maleinized hemp oil, $\mathrm{MLO}=$ maleinized linseed oil 
Table S2 DMA data of the neat PLA and PLA-MIECO blends

\begin{tabular}{|l|l|l|}
\hline Samples & Storage modulus $(\mathrm{MPa})$ at $25^{\circ} \mathrm{C}$ & Glass transition temperature $\left({ }^{\circ} \mathrm{C}\right)^{*}$ \\
\hline PLA & $2792 \pm 46$ & $71.2 \pm 0.3$ \\
\hline PLA-MIECO5 & $2597 \pm 24$ & $66.7 \pm 0.2$ \\
\hline PLA-MIECO10 & $2312 \pm 21$ & $65.2 \pm 0.2$ \\
\hline PLA-MIECO15 & $2270 \pm 17$ & $65.2 \pm 0.2$ \\
\hline
\end{tabular}

* Glass transition temperatures were determined from peak temperatures of the tan delta curves

\section{References}

1. Liu, W. D.; Qiu, J. H.; Fei, M. E.; Qiu, R. H.; Sakai, E., Manufacturing of Thermally Remoldable Blends from Epoxidized Soybean Oil and Poly(lactic acid) via Dynamic CrossLinking in a Twin-Screw Extruder. Ind Eng Chem Res 2018, 57 (22), 7516-7524.

2. Mauck, S. C.; Wang, S.; Ding, W. Y.; Rohde, B. J.; Fortune, C. K.; Yang, G. Z.; Ahn, S. K.; Robertson, M. L., Biorenewable Tough Blends of Polylactide and Acrylated Epoxidized Soybean Oil Compatibilized by a Polylactide Star Polymer. Macromolecules 2016, 49 (5), 1605-1615.

3. Quiles-Carrillo, L.; Montanes, N.; Lagaron, J.M.; Balart, R.; Torres-Giner, S. On the use of acrylated epoxidized soybean oil as a reactive compatibilizer in injection-molded compostable pieces consisting of polylactide filled with orange peel flour. Polym. Int. 2018, 67 (10), 1341-1351.

4. Quiles-Carrillo, L.; Duart, S.; Montanes, N.; Torres-Giner, S.; Balart, R. Enhancement of mechanical and thermal properties of injection-molded polylactide parts by addition of acrylated epoxidized soybean oil, Mater Des, 2018, 140, 54-63.

5. Quiles-Carrillo, L.; Blanes-Martínez, M.M.; Montanes, N.; Fenollar, O.; Torres-Giner, S; Balart, R.; Reactive Toughening of Injection-molded Polylactide Pieces by Maleinized Hemp Seed Oil, Eur Polym J, 2018, 98, 402-410.

6. Liu, W. D.; Qiu, J. H.; Fei, M. E.; Qiu, R. H.; Sakai, E., Manufacturing of Thermally Remoldable Blends from Epoxidized Soybean Oil and Poly(lactic acid) via Dynamic CrossLinking in a Twin-Screw Extruder. Ind Eng Chem Res 2018, 57 (22), 7516-7524.

7. Ferri, J. M.; Garcia-Garcia, D.; Montanes, N.; Fenollar, O.; Balart,; R. The effect of maleinized linseed oil as biobased plasticizer in poly(lactic acid)-based formulations. Polym. Int. 2017, 66 (6), 882-891.

8. Carbonell-Verdu, A.; Garcia-Garcia, D.; Dominici, F.; Torre, L.; Sanchez-Nacher, L.; Balart, R., PLA films with improved flexibility properties by using maleinized cottonseed oil. Eur Polym J 2017, 91, 248-259. 